\title{
Missing: Understanding the Reception of a Serious Game by Analyzing App Store Data
}

\author{
Marcus Toftedahl ${ }^{1}$, Per Backlund ${ }^{1}$, Henrik Engström ${ }^{1}$ \\ ${ }^{1}$ Division of Game Development, School of Informatics \\ University of Skövde \\ \{marcus.toftedahl, per.backlund, henrik.engstrom\}@his.se
}

\begin{abstract}
The focus of this paper is the design and player reception of a serious game called Missing released on Google Play with the intention of spreading awareness of trafficking and its impact on individuals and society. The aim of the paper is to investigate how the game has been received by its players, focusing on its trafficking theme, by analyzing player metrics and app store data available from the Google Play digital distribution system. The paper presents results focusing on three main knowledge contributions: the identification and characterization of the tension between the designer's intention with a game's mechanics and how they help to convey the message of the game, the identification of the complexity of finding relevant reviews relating to the serious theme of the game and the identification and characterization of the tension between the star rating and the content of the reviews. One of the conclusions is that even a negative review can mirror a positive result in terms of fulfillment of the purpose.
\end{abstract}

Keywords: Serious games, Games for change, Trafficking, Smartphone, App store, Metrics

\section{Introduction}

Digital games of today is a media form mature enough to tackle serious subjects. This is reflected in the serious games sector focusing on using games for purposes beyond pure entertainment [1-3]. One example of such a serious game is Missing [4], a game developed in India by Flying Robot Studios and published by Missing Link Trust. Missing is a game developed with the ultimate purpose to end demand of trafficking for sexual exploitation. To address this problem, Missing lets the players experience the horrors of a trafficking process through the perspective of a young girl who is abducted from her home and put in a red light district. By using an interactive game, the developers intend to let the players "feel the story" through both game mechanics and narrative. With this setup, the developer aims to let players experience trafficking from a victim's perspective and thereby hope to inflict a change in the attitude towards prostitution. With Missing, the developers specifically want to target a male audience (by making the assumption that a large amount of gamers are men). To reach this audience, Missing is released on common digital distribution channels where gamers usually consume games. In this case, Missing is available on smartphones through the Google Play and Apple iTunes app stores.

Trafficking is a complex global social issue where young people, in most cases women, are abducted and forced into prostitution on a location far away from their origin [5]. According to statistics from the United Nations Office on Drugs and Crime (UNODC) trafficking is a large and increasing problem in several regions of the world [5]. However, the problem as such is not easy to grasp or to remedy, but as previous research has shown games can be a powerful medium to embrace so called "wicked problems" (cf. [6-9]), i.e. problems seemingly impossible to solve due to their complex nature [10], to at least communicate its complexities and give a deeper understanding of the issue. The focus of this paper is the 
design, development and player reception of Missing, concentrating on its purpose of ending the demand for trafficking for sexual exploit.

Since the distribution of Missing is done with commercially available digital app stores, in this case primarily Google Play, the end user will play the game in an informal setting. This means the players will meet the purpose of the game by "unintentional learning", i.e. to play the game and find the purpose through playing the game as a COTS game [11]. Due to this, there are limited means of measuring the impact of the game by using traditional evaluation methods. One viable option to remedy this is to rely on the data available from the distribution channel's data collection functions, i.e. player reviews and ratings. To use such data for evaluation of the success of a game is common in the entertainment game industry but for a serious game it is a rather novel approach $[8,12]$.

The aim of the paper is therefore to investigate (1) how the game design vision has been implemented into a game available to download for free on smartphone devices, and (2) how the game and its specific purpose has been received by its players by analyzing player metrics and data derived from the Google Play app store.

\section{Related work}

Previous research has pointed to the benefit of using games to address "wicked problems". Wicked problems are issues with deep and complex connections between a multitude of variables, where both the connections and the variables themselves are hard to identify and understand $[9,13]$.

Games can be a powerful form of media in embracing difficult areas including such wicked elements, thanks to the interactive nature of a game. The players are allowed to experiment with potential solutions in a safe setting and thereby creating their own mental images of the problem [9]. Examples of games taking on issues in this domain include Papers, Please [14], That Dragon, Cancer [15] and This War of Mine [16]. These games come with a specific subject or theme in focus (immigration, grief and the impact of war on civilians, respectively) and are distributed through digital app stores such as Steam, Google Play or Apple iTunes. While not always marketed as serious games as such, they do contain serious themes.

The development of This War of Mine has been studied by de Smale et al. [6] describing the game design process with a focus on the handling of moral issues from the developers' point of view. The design and subsequent implementation of This War of Mine has formed a game experience where strong elements of discomfort and boredom are integral parts of the game mechanics. The game mechanics together with the narrative have the intention to achieve an emotional response in the player highlighting the game's purpose of "...provide an emotionally realistic experience of war from a civilian perspective" [6].

To reach the desired purpose of This War of Mine, continuous testing of the game on the target audience was a key factor to ensure that the design vision was received by the players and that the balance between entertainment and seriousness was right [6]. The continuity in testing during development is also highlighted in the case of the development of a HIV prevention game, PlayForward: Elm City Stories [8], where player testing was a vital part of the development focusing both on purpose and content but also the general functions of the game. If the game is not functioning well in any case, both technically or progress-wise, the opportunity to make an impact may be lost. But, as Hieftje et al. [8] point out, there is a need for discussing different methods of data collection and analysis, both with respect to the standardized assessments used in serious games research as well as using in-game data. 


\subsection{Balancing "serious and entertainment" goals}

Games can be used for serious purposes based on their motivational and engaging characteristics, with an intention to tap on to the gaming aspect to reach their intended purpose [17]. As described previously, the inclusion of elements of discomfort or non-entertaining elements to further highlight the theme or the specific purpose of the game may disturb the balance between the entertainment traits of the game and the specific characteristics of the game's purpose [6, 8].This "serious vs. entertainment" balance is discussed by Schreiner [18] where an interview study was made with developers of games for social change concentrating on topics such as fun in relation to serious games. One of the conclusions is that the "fun" factor stems from the common view that games can attract the attention of its players to learn from an activity. Charsky [19] discusses this balance as well, and one conclusion is that there is no single solution to such a balance, but it is stated that the combination of game characteristics and pedagogical elements is to be strived for.

Even though "fun" or "entertainment" can be found in several definitions the serious games term (cf. $[2,3,20,21])$ the inclusion of "having fun" as a desired emotional response even in entertainment games can be debated [22]. To be able to design a game that has mechanics supporting the theme or purpose of a game, the MDA framework (Figure 1) [22] can be used as a design framework. The framework is intended to function as a design tool, but also an analysis tool to view the game from both the lens of a designer as well as a player. The MDA framework consists of three main characteristics; the Mechanics, i.e. the actions and behaviors given to the player within the game context designed by a game designer which creates Dynamics at run time, (i.e. when the game is played) invoking a desired Aesthetics (i.e. emotional response) in the player.

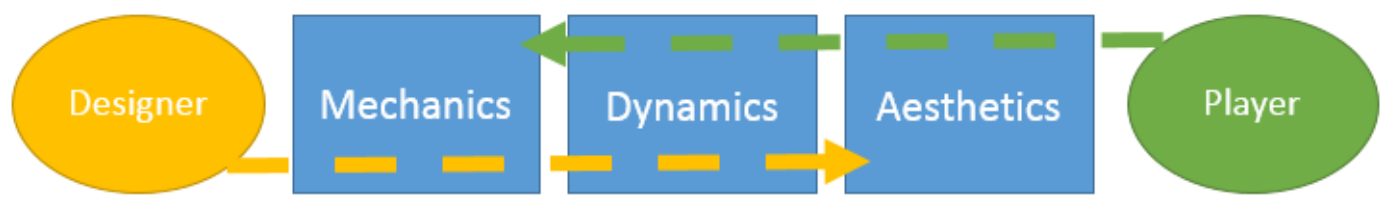

Figure 1. The MDA framework, proposed by Hunicke, LeBlanc and Zubeck [22]

Used as a design and development framework, MDA emphasizes the dual perspectives of a game, i.e. to include both the developer as well as the player perspective. From a player perspective, the starting point is the aesthetics where the perceived tone or feeling of the game is formed by the observable dynamics at run-time, which in its turn is based on the mechanics [22]. The dynamics component is hard to design and plan for, thus player testing is needed to understand the dynamics happening at run time. The aesthetics can be described as the "fun" of the game, with fun put in quotation to stress the fact that "fun" is a problematic term when designing games even for entertainment purposes. With the MDA framework, the authors propose to move away from "fun" as a desired emotional response and instead use a more directed vocabulary describing the specific intended goal aesthetic of the game.

While the MDA framework can be used as a lens for designing and analyzing games, the serious games continuum [2] can be used to define and classify serious games and discuss and plan for the serious and entertainment components. The serious game continuum is divided into a number of categories where a game can be positioned to further define its serious use. The serious game continuum provides a definition of serious games as a digital game, simulation or virtual environment where the player can engage in activities through responsive narrative, gameplay or encounters in order to inform, influence or convey meaning. In connection to this, the continuum can be a tool to understand the purpose and usage context of a game better using a scale ranging from games for purpose to experiential environments with minimal or no gaming characteristics (Figure 2) [2]. 


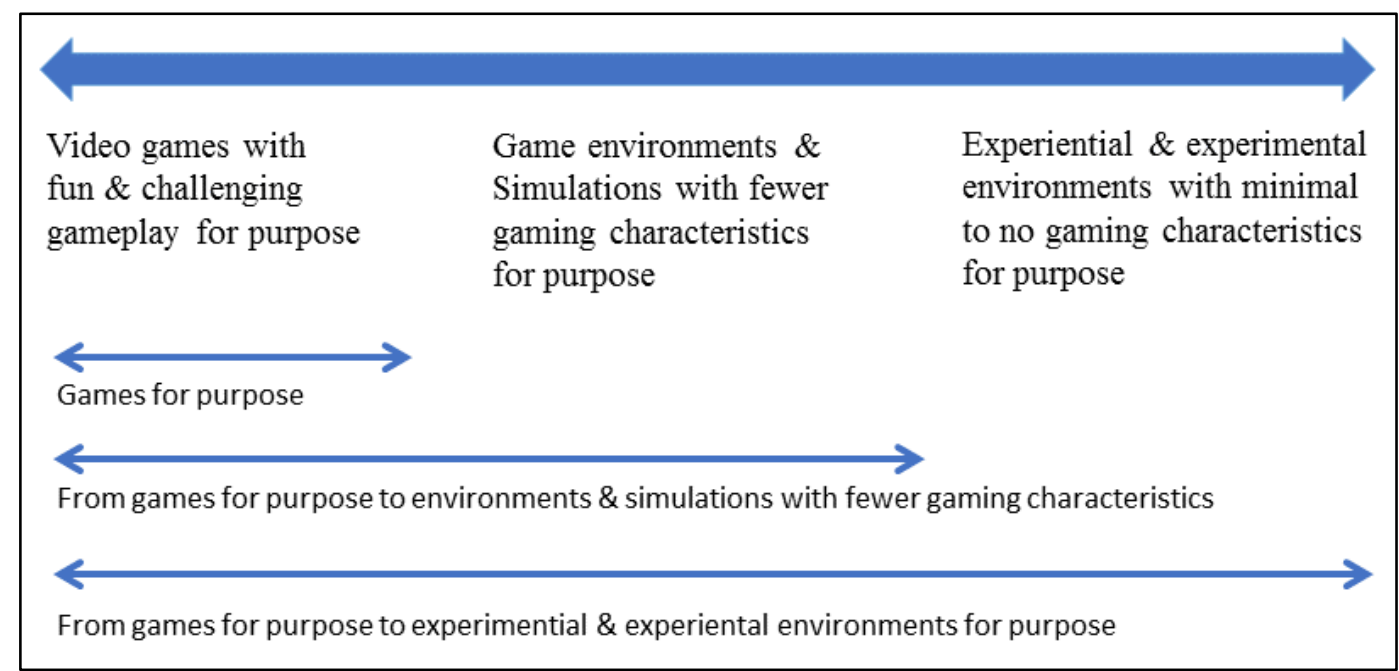

Figure 2. The serious game continuum, proposed by Marsh [2]

The purpose and subsequent reception of a serious game is discussed by Marsh [2]; where the success of a serious game is measured by how well its purpose is fulfilled. To achieve this fulfillment of purpose, the game in question should contain characteristics making a game successful- and add the specific "serious" purpose upon this [2].

\subsection{App store analysis methods}

To use available app store data to understand the reception of a released app is a topic that have received interest from both researchers and practitioners. With apps distributed through a digital distribution channel, the developer (and to some extent the general public) can access data regarding the app in question. App data aggregator services such as AppAnnie [23, 24] or Appfigures [24] use the publically available data to give an automated analysis of the reception of an app. Tools similar to these are included into the distribution platform, where persons with developer access can access necessary data. To use the available data to understand the success of an app has become a vital tool for app developers, but the sheer amount of data can make analysis difficult. The aforementioned automated data aggregation and analysis services are examples designed to help handling the data, and from a research perspective there has been work trying to structure app store data into usable feedback. Fu et al. [25] propose a model, WisCom, using three levels of analysis; Macro Level (Market analysis), Meso Level (Per app analysis) and Micro Level (Per review analysis). Using WisCom, the authors could find inconsistencies between the user review and the ratings given and also give an indication on why users like a specific app. Maleej and Nabil [26] propose similar ideas of using automated processes to classify reviews into different categories. Using natural language processing techniques the authors have designed a system to automatically tag user reviews as Bug reports (technical problems), Feature requests (asking for missing functionality), User experiences (reflecting on the personal experience) and Ratings (text description corresponding to the star rating). Guzman and Maalej [27] propose an automated method focusing on analyzing app store reviews to produce summaries regarding users' opinions of an app. Common for all these approaches is that they rely on some sort of automated textual analysis and classification.

\section{Research questions and method}

The quality or success of a serious game can be measured based on how the purpose of the game has been fulfilled [2]. Also, a well-functioning game is important (cf. [8, 9, 22]). Using player metrics from serious games in conjunction with existing evaluation methods has been previously identified as an area where more research is needed [8] and this paper aims to 
contribute to the area by focusing on using data available from commercially available distribution channels. In contrast to previous research on app store analysis methods [25-27] this paper is limited to using currently available systems to analyze the perception of the serious aspects of a game, not focusing on creating new analysis tools. Furthermore, the use of mobile phones as a platform and its related distribution channels for distributing serious games is an area of research needing more attention; in a literature review consisting of 143 serious games projects only two (2) mobile games were identified [11]. Our research helps to start filling this gap.

The research question is formulated as: "How has the intended anti-trafficking theme in Missing been received by its players?"

To answer this question, two objectives were achieved: (1) to describe how the game design vision based on real trafficking victim's stories have been implemented into a game, and (2) to investigate how the game and its specific purpose has been received by its players.

The research has been carried out using a longitudinal case study with two main sources of data collection. The game design vision is investigated by participation in post-production meetings, interviewing the developers and getting access to relevant production material including game design documents and the game itself. The reception of the game has been investigated by analyzing data available from the Google Play Console.

The researchers first met the developers of Missing in November 2016 during a presentation at the Nasscom Game Developers Conference in Hyderabad, India, and have since then followed the project and its further development. The case was selected since it can fill the identified gap concerning serious games delivered on mobile platforms and since it addresses a sensitive and important topic. This has allowed the researchers to take part in meetings and discussions regarding the game and its subsequent updates, its reception and other general development questions. During the period from November 2016 to June 2017 the researchers participated in 11 Skype meetings regarding the game, its updates, further development and reception. Each Skype session lasted approximately 1 hour and usually handled questions regarding player reception focusing on bug fixing and localization. This continuous contact has also led to the possibility to get access to and permission to use production documents, i.e. design documents and documents regarding game mechanics and narrative. This information has served as a basis for the game description in chapter 4. A focused and more comprehensive interview has been conducted in person on site in India. The interview was carried out using a semi-structured interview setup covering three topics: the development of the game; the localization of the game (from English to Bengali) and the implementation of the anti-trafficking theme focusing on game mechanics and narrative design. The interview was recorded and transcribed.

Access to the Google Play data has been given to the researchers by full granting developer access rights to the Google Play Console. The data from Google Play Console has been analyzed using both the auto-generated data sets compiled by the Google Play system manually by using the raw data in csv-files. The manually analyzed data is what Fu et al. [25] on a macro level, i.e. the per review analysis. The analysis is described in more detail in Chapter 5.

The research has followed the ethics guidelines from the Swedish Research Council [28] and permission to use information from production documents, meetings, interview sessions, media from the game (i.e. screenshots, sound and video) as well as Google Play data has been given to the researchers by the informants, including quotation rights. The informants have been given the opportunity to check any factual and quotation errors before the submission of the paper. 


\section{The design of Missing - from idea to execution}

The development of the game Missing started in the spring of 2016 as a part of an over-arching anti-trafficking campaign by the organization Missing Link Trust. An Indian game development studio, Flying Robot Studios, was contracted for the development of the game Missing. The development was carried out in close collaboration between the game studio and the Missing Link Trust organization. The storyline of Missing is based on interviews with trafficking victims, where the game developer with the aid of the project leader for Missing Link Trust met and interviewed persons who have been in and rescued from trafficking situations in India. The narrative of Missing is based on these interviews, but the game is described by the organization as a fictional work based on true stories and does not portray any actual persons or specific events. The first version of the game was released on Google Play and Apple iTunes app stores in October 2016.

As stated previously, Missing's main purpose is to spread awareness of trafficking through a digital game. This is done by letting the player take the perspective of a trafficked girl and to follow and guide her through her struggle to flee from the situation she finds herself in. The narrative of the game follows a traditional three act structure; with a beginning, a middle and an end divided into three separate chapters. The three chapters contain different objectives for the player to reach, all connected to the story using game mechanics supporting the narrative.

The game design, including the narrative design and game mechanics, is based on interviews with trafficking victims. The lead game developer of the project, involved in all aspects of the development, describes the development process as such:

"Actually the story dictated the mechanics. Not the other way around which generally

is the norm. I had written the story first and found suitable mechanics to convey the

feelings. [...] there are several areas where I used game mechanics to 'feel' the story rather than 'telling' it. Much [more] effective."

\section{- Personal interview with the lead game developer of Missing}

The story for the game was created first and it dictated the game mechanics. Since the game is short with a total play time of approximately two (2) hours, the risk of repetitive game play was planned to be kept to a minimum. The developer describes these main game mechanics as environmental and micromanagement-based puzzles.

"The game mechanics are really a combination of two types of puzzles: environmental and micromanagement."

\section{- Personal interview with the lead game developer of Missing}

Using the serious games continuum [2] as a lens when analyzing Missing, the game is placed in the leftmost part of the continuum: a game with "fun \& challenging gameplay for purpose". The general characteristic of Missing is that it is using gameplay and narrative to invoke discomfort in the player, with the purpose of changing the attitude towards trafficking. This is similar to the ideas presented in connection to the design of This War of Mine [6] and other games in the same domain [18].

Since the game mechanics are tightly linked to the anti-trafficking theme throughout the story, the game has the characteristics that the leftmost part of the serious games continuum presents. In relation to this, Missing is not trying to simulate an accurate description of all factors of the trafficking problem, but focus on a few common characteristics. 
The following description of Missing is divided into tables corresponding to the chapters found in the game. The main game mechanics (the actions the player can perform) and the main aesthetics (the intended emotional response in the player) are analyzed using MDA as a lens. The chapters are presented in separate tables, providing information about the story synopsis, the main mechanics of the chapter as well as the intended aesthetics.

Table 1. Overview of game chapter 1.

\begin{tabular}{|c|c|}
\hline Chapter title & "Death of Innocence" \\
\hline Story synopsis & $\begin{array}{l}\text { The first chapter sets the scene and tone of the game and introduce the } \\
\text { player to the characters and the environment. The setting of the first } \\
\text { screen of the game presents the player with a cell-like room (Figure 3) } \\
\text { with a girl sitting on a bed. The girl on the bed is the player character } \\
\text { (PC), whose name originally is Champa (later given the name Ruby by } \\
\text { the brothel owner). During the first scene the player is introduced to a } \\
\text { number of non-player characters (NPCs), including Masi, the brothel } \\
\text { owner. Masi has is the antagonist of the story. By exploring the } \\
\text { environment and by interacting with the NPCs the player get to know } \\
\text { that Champa/Ruby does not know anything regarding her abduction or } \\
\text { current location. }\end{array}$ \\
\hline $\begin{array}{l}\text { Main } \\
\text { mechanics }\end{array}$ & $\begin{array}{l}\text { Environmental puzzles } \\
\text { - Navigate through maze-like corridors } \\
\circ \text { Limited visual aids and pointers where to go } \\
\text { - Find key objects to progress } \\
\circ \text { Hidden somewhere in the corridor section } \\
\text { - Avoid guards } \\
\circ \text { Guards patrolling the perimeters. Getting caught means } \\
\text { restart. } \\
\text { Dialogue } \\
\text { - Interactive dialogue system, with the purpose of: } \\
\circ \text { Further the story } \\
\circ \text { Give objectives to the player }\end{array}$ \\
\hline Main aesthetics & $\begin{array}{l}\text { Invoke a sense of helplessness and frustration over the situation } \\
\text { - Unfair balancing of guard presence, i.e. it is easy to get caught } \\
\text { - Unclear where to go in the labyrinth, i.e. trial and error elements } \\
\text { to navigate } \\
\text { - The brothel owner renaming the main character to a new name, } \\
\text { i.e. stripping the player character of identity }\end{array}$ \\
\hline
\end{tabular}

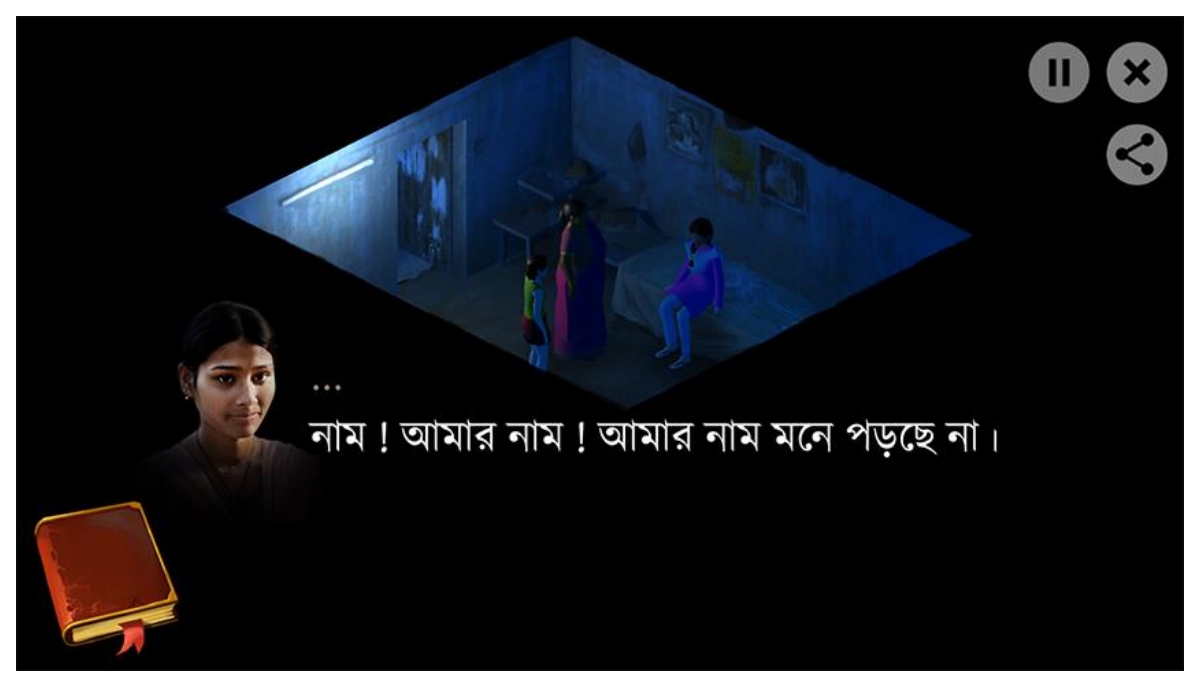

Figure 3. Screenshot from Missing - Chapter 1. 
Table 2. Overview of game chapter 2.

\begin{tabular}{|c|c|}
\hline Chapter title & "Life of a Whore" \\
\hline Story synopsis & $\begin{array}{l}\text { The chapter is introduced with a quote from Masi: "Ruby, you are one } \\
\text { of us now. Let me teach you tricks of this trade." The player is presented } \\
\text { with a view over a section of the "red light district" where the brothel } \\
\text { is located (Figure 4). Several NPCs are seen on screen, both female and } \\
\text { male. The male NPCs are customers that the player can attract to buy } \\
\text { sex. The female are prostitutes in the brothel, including Champa/Ruby. } \\
\text { The main task in this chapter is to earn enough money to reach the daily } \\
\text { monetary goal set by Masi. If the target is reached, Champa/Ruby will } \\
\text { eventually gain the trust of Masi and thus be able to take short breaks } \\
\text { to explore the surrounding neighborhoods. Doing so will reveal a } \\
\text { possibility to get help by the Missing Girls Hotline, a help organization } \\
\text { focusing on rescuing trafficking victims. }\end{array}$ \\
\hline Mai & $\begin{array}{l}\text { Micro-management } \\
\text { - Daily income must be reached to avoid punishment } \\
\text { - Sex buyers can be attracted by the player } \\
\circ \text { Player requests a price for Champa/Ruby's body } \\
\circ \text { Treating sex buyers with alcohol increase the chance } \\
\text { of getting a high price } \\
\circ \quad \text { The higher price asked, the less time to reach the daily } \\
\text { income, but also less chance of getting a high price } \\
\text { accepted } \\
\text { A lower price attracts more customers, i.e. less time } \\
\text { consuming and less money earned per sale } \\
\text { The player must balance the price of Champa/Ruby's body in } \\
\text { the role of Champa/Ruby to avoid punishment from the brothel } \\
\text { owner }\end{array}$ \\
\hline Main aesthetics & $\begin{array}{l}\text { Invoke a sense of hopelessness and frustration over the situation } \\
\text { - The constant pressure of pricing Champa/Ruby according to } \\
\text { the current demand } \\
\text { - Not meeting the set demand/monetary goal renders a } \\
\text { punishment adding on to the sense of hopelessness and } \\
\text { frustration } \\
\text { - Meeting the set demand renders a relief of not getting extra } \\
\text { punishment, but still the situation of pricing Champa/Ruby } \\
\text { remains }\end{array}$ \\
\hline
\end{tabular}

Figure 4. Screenshot from Missing - Chapter 2

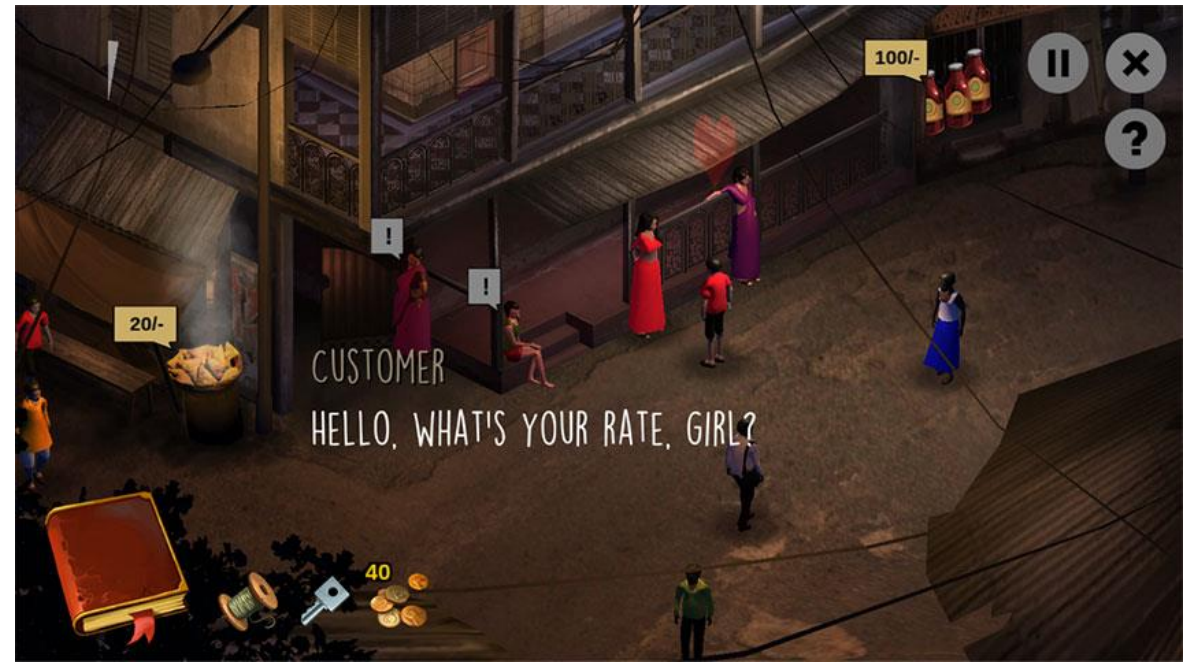


Table 3. Overview of game chapter 3.

\begin{tabular}{|l|l|}
\hline Chapter title & "Life of a Whore" \\
\hline Story synopsis & $\begin{array}{c}\text { The glimpse of hope is the main focus for the third and final } \\
\text { chapter. Finding that there are a possibility to get help is the main } \\
\text { objective. One of the tasks is to find the "Missing girls silhouette" } \\
\text { (Figure 5) where a telephone number to the Missing Girls Hotline can } \\
\text { be found. Doing so will eventually result in the rescue of Champa and } \\
\text { the game is concluded with a scene where she is on her way home, far } \\
\text { away from the red light district. }\end{array}$ \\
\hline Main mechanics & $\begin{array}{c}\text { Environmental puzzles } \\
\text { Navigate through maze-like corridors } \\
0 \text { Limited visual aids and pointers where to go }\end{array}$ \\
$\begin{array}{c}\text { Find Missing Hotline Number } \\
\circ \text { Hidden somewhere in the surroundings } \\
\circ \text { Call for help }\end{array}$ \\
$\begin{array}{c}\text { Avoid guards } \\
\circ \text { Guards patrolling the perimeters. Getting caught } \\
\text { means restart. }\end{array}$ \\
$\begin{array}{c}\text { Dialogue } \quad \text { Interactive dialogue system, with the purpose of: } \\
\circ \text { Further the story } \\
0 \text { Give a glimpse of hope, that there are someone able to } \\
\text { help }\end{array}$ \\
\hline Main aesthetics & $\begin{array}{c}\text { Invoke a glimpse of hope, there is help to be found } \\
\text { Finding the Missing Hotline Number provides a pointer to a } \\
\text { way out of the situation }\end{array}$ \\
\hline
\end{tabular}

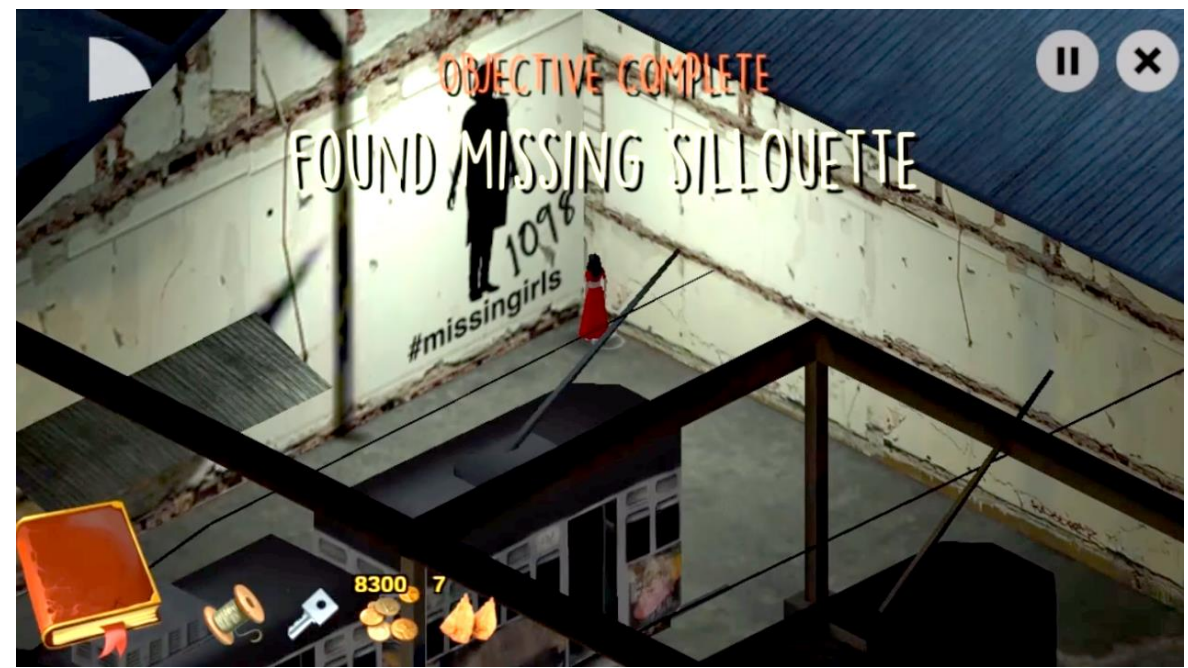

Figure 5. Screenshot from Missing - Chapter 3.

\section{Analysis}

To understand how Missing and its theme has been received by the players, an analysis of the Google Play app store data has been made using two analysis methods: (1) using the automatic data analysis tools provided in the Google Play Console (i.e. star ratings, number of downloads, auto-generated analyses of the reviews) presented in chapter 5.1, and (2) by manually analyzing the data sets accessible in raw format from the Google Play Console (i.e. qualitative and quantitative data in csv-files) presented more in depth in chapter 5.2. The data used in this paper is from the period October 2016 to December 2017. 
Since none of the systems or methods of app store data analyses exemplified in chapter 2.2 have been made publically available, app developers must rely on systems that are accessible. The systems already built in the app store are easily accessible and, for the developer, all the relevant data related to the app is available.

\subsection{Auto-generated data analyses}

Missing has received positive reviews in general with an average star rating of 4.32 out of 5 stars. The Google Play Console gives developers an overview of both qualitative and quantitative data related to an app including automatically generated data compilations, such as the map data presented in Figure 6 and automated analysis of the text derived from player reviews presented in Figure 7. These automatically generated data compilations can be useful to get a quick overview of trends and general attitudes towards the app in question, but can be problematic for a more thorough analysis of specific questions related to the app.

The developers of Missing have the intention to spread their message primarily to the local region around the Indian subcontinent and to areas where trafficking and prostitution are problems in focus. One useful feature to see if this goal has been achieved is to look at the "Installs by user" map (Figure 6).

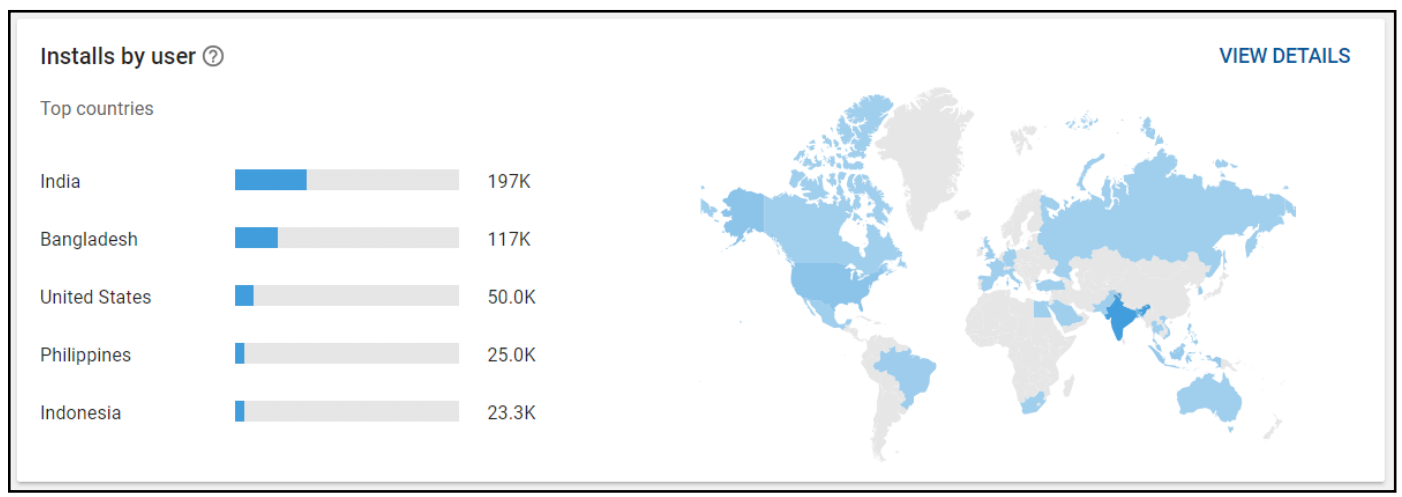

Figure 6. Top 5 countries in which Missing has been downloaded. The figure is a screenshot from Google Play Console.

The map and its related metrics shows that 197,000 of the installs are from India and 117,000 of the installs from Bangladesh, making the local region related to the game's theme and development, account for approx. $63 \%$ of its total install base. The region on third place, the US, has 50,000 of the installs, followed by the Philippines and Indonesia with approx. 25,000 installs each.

To get an understanding of how the game has been received by the players, more detailed feedback is of interest. The rating is one indicator and in addition to the numerical star rating a free-text review can be made by each user. Since it is a time consuming task to manually go through each and every review, the system provides auto generated analyses based on the review data. This is an automated function within Google Play Console and the developer has little or no control over how the data is processed and presented, i.e. it is less reliable, but also less time consuming, compared to a manual analysis. In the auto generated analyses, certain keywords are used to group review content into different topics and themes. The developers can then get a quick overview of the most common themes based on keywords from the reviews without having to read through all text manually.

Two versions of the function can be used; Benchmarks, where the app is compared to other apps in the same category using a common set of topics, and Topics where a dynamic set of topics derived from common themes in the reviews of the app is used to form the categories.

Figure 7 shows the Benchmark section of Missing and how it has been received in relation to the fixed set of topics compared to apps in the same category. Since Missing is categorized as an Adventure game, the comparison is made in relation to other apps in this category. 


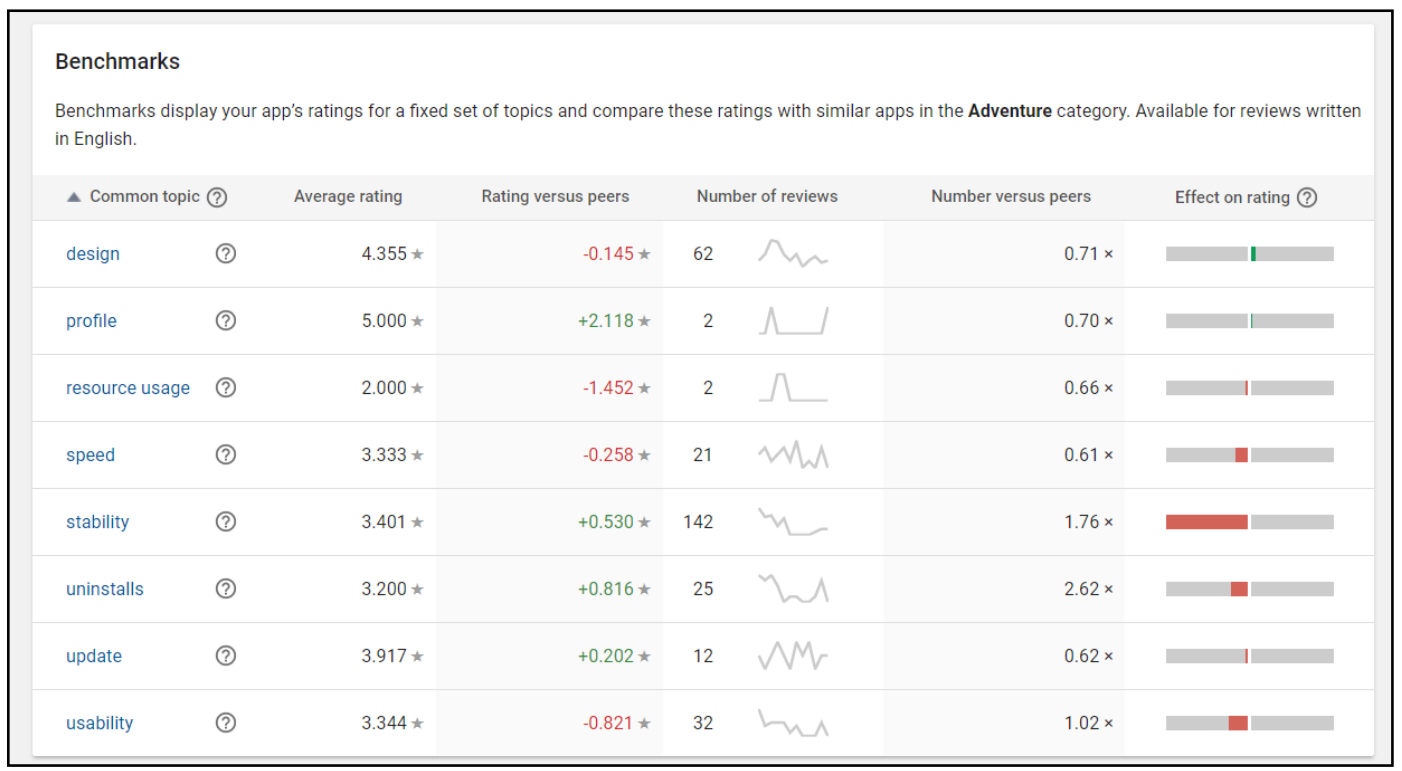

Figure 7. The Benchmark section of Missing, comparing the app to other apps in the Adventure category. The Common topics are pre-defined and relates to all apps in the specific category.

With this function the developer can get an overview of how the app in question is performing by looking at the Rating versus peers and Number versus peers, comparing the metrics of the app to the others. In this case, Missing has a high average rating based on the "design" topic but compared to its peers in the same genre the rating is -0.145 in the design category. According to the explanation available in the help section of Google Play Console the topic is based on reviews that mention the app's visuals, including review text such as "[...] graphics, beautiful game, looks good, etc."

The topic can be explored in more detail, revealing the reviews upon which the analysis is based. For Missing, the "design" topic is based on reviews mainly containing words related to the graphical design of the game, but also where the reviewers are using words such as "beautiful" in other contexts than graphics. This can be seen in Figure 8, where one user mentions the "beautiful storyline" but also mentions the graphics in the same sentence. The highlighting of certain words is done by the system to indicate what keywords the analysis is based on.

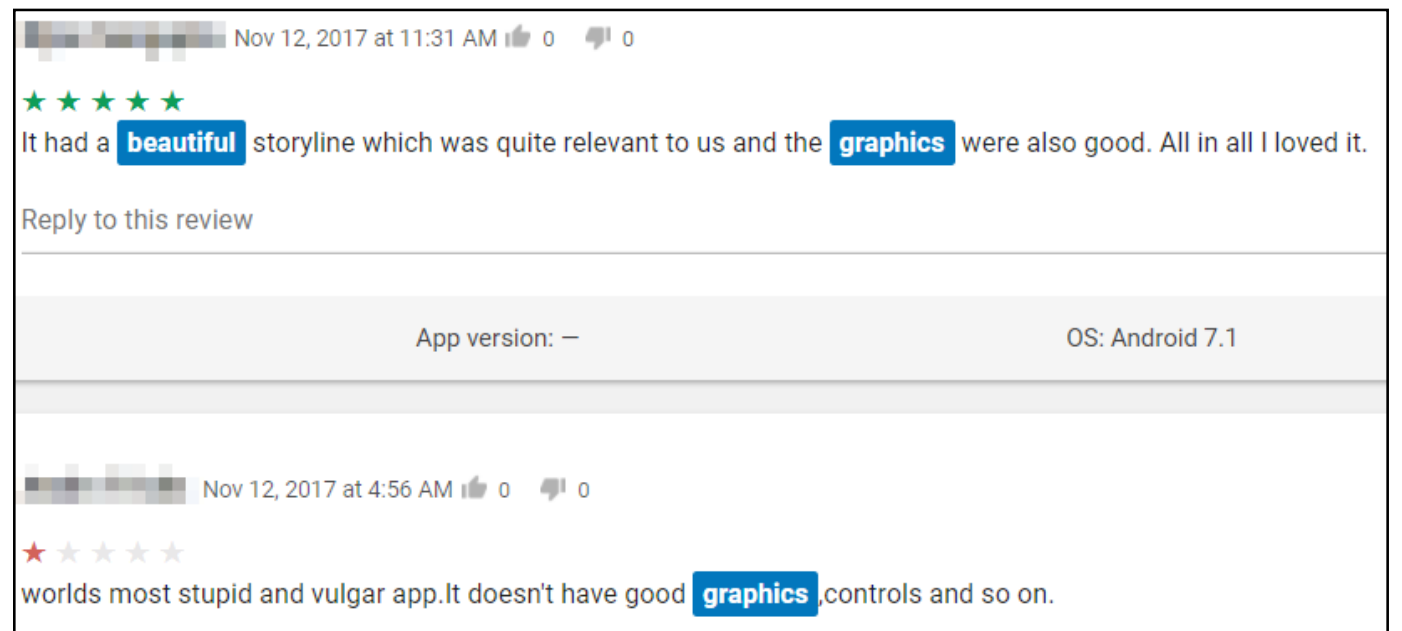

Figure 8. Details from accessing the "design" topic in the Benchmark automated review analysis. 
pag. 14

The second automated review analysis function in Google Play Console, Topics, is sorted into topics derived from the reviews for the specific app (Figure 9). Related to Missing, the "engagement" topic would be relevant to understand the reception of the purpose. The "engagement" topic is based on 41 of the reviews, but since the topics are generated based on the reviews of the specific app there is no information in the Google Play Console explaining inclusion criteria or keywords. To get an understanding of what information from the reviews the "engagement" category is based on, the function where the reviews are displayed and keywords are highlighted is vital.

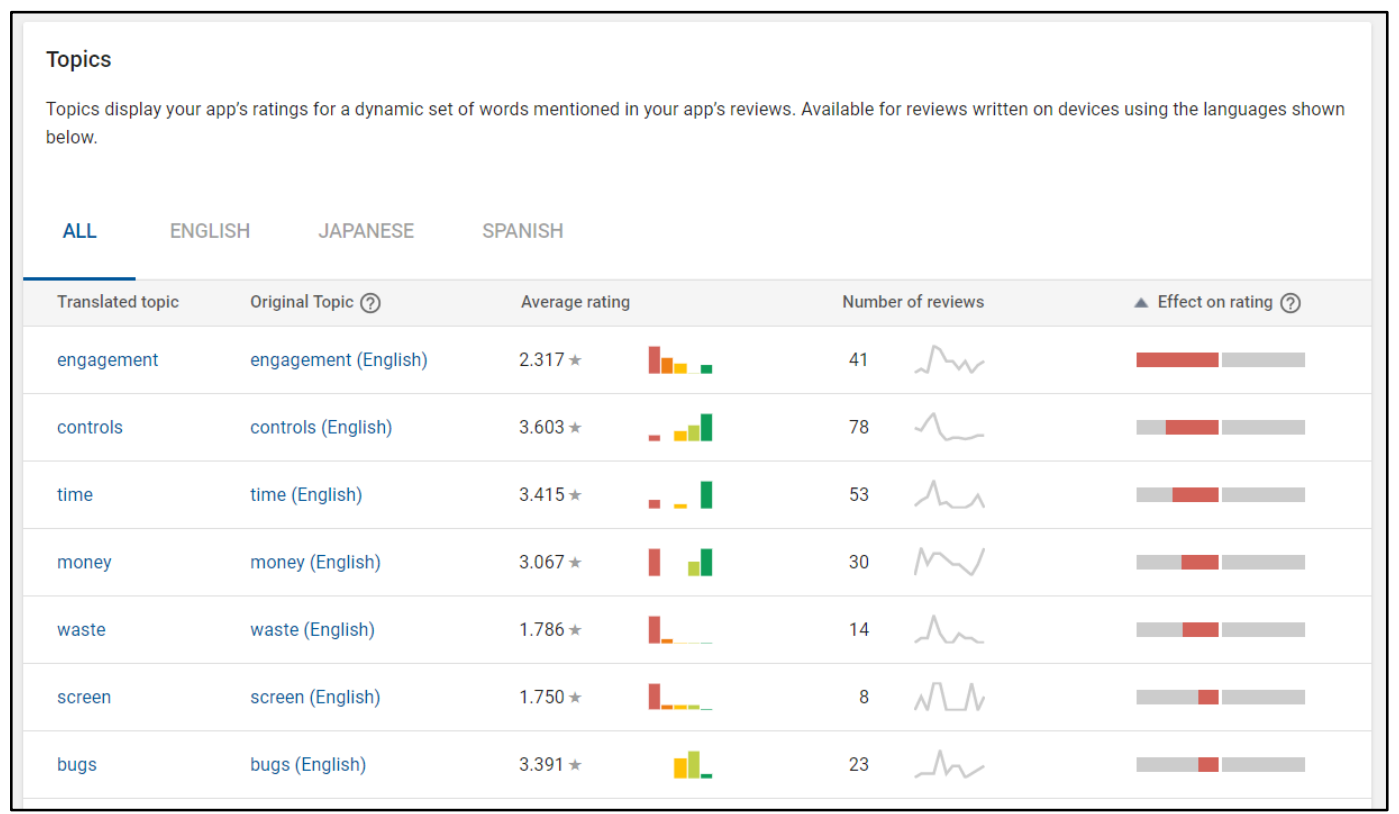

Figure 9. The Topics section of the auto generated review analysis function in Google Play Console. The topics are derived from the review data from Missing.

Exploring the "engagement" topic deeper reveals that the reviews the topic is based on contain keywords such as "addicted" and "boring" (Figure 10). The system has identified that the "engagement" topic have a negative impact on the overall reviews, and most of the 41 reviews are in the same style as the two depicted in Figure 10.

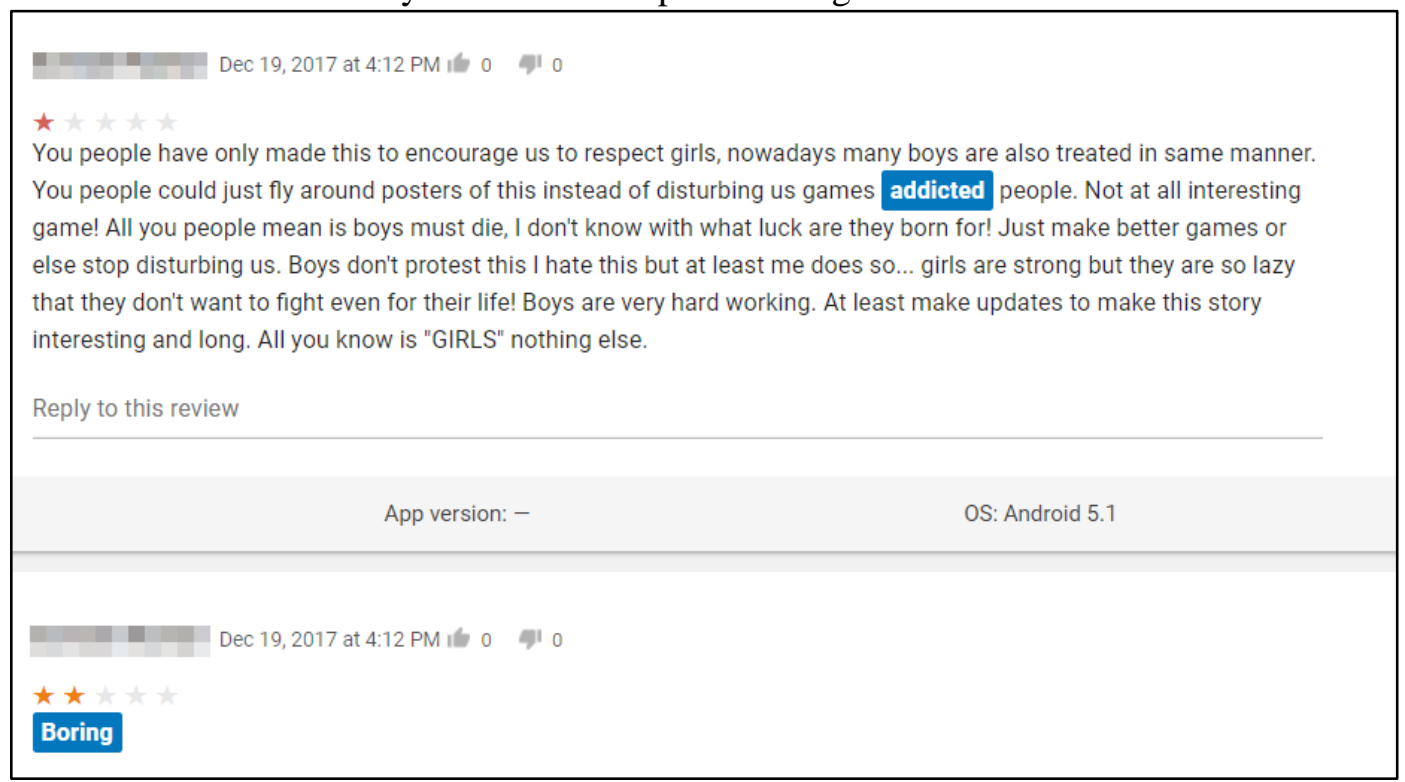

Figure 10. Example of reviews the "engagement" topic of the Topics section is based on. 
Google Play Console also offers tools where quantitative data is processed automatically. The quantitative data provided is mostly based on number of installs and star ratings. One example of this, seemingly useful to understand how popular the app has been over time is the "Installs by user" function. A graphical representation of the install statistics for Missing can be seen in Figure 11, where the installs per day is displayed in a graph. The graph shows that downloads started in larger quantities during late 2016, coinciding with the Nasscom Game Developer Conference 2016 in India where Missing was awarded with the "Best Indie Game" prize. The second point of interest is the download spike during the spring of 2017, coinciding with an updated version of the game. With this update Missing was localized into Bengali. A majority of downloads during that spike originated from Bangladesh, where Bengali is one of the major languages.

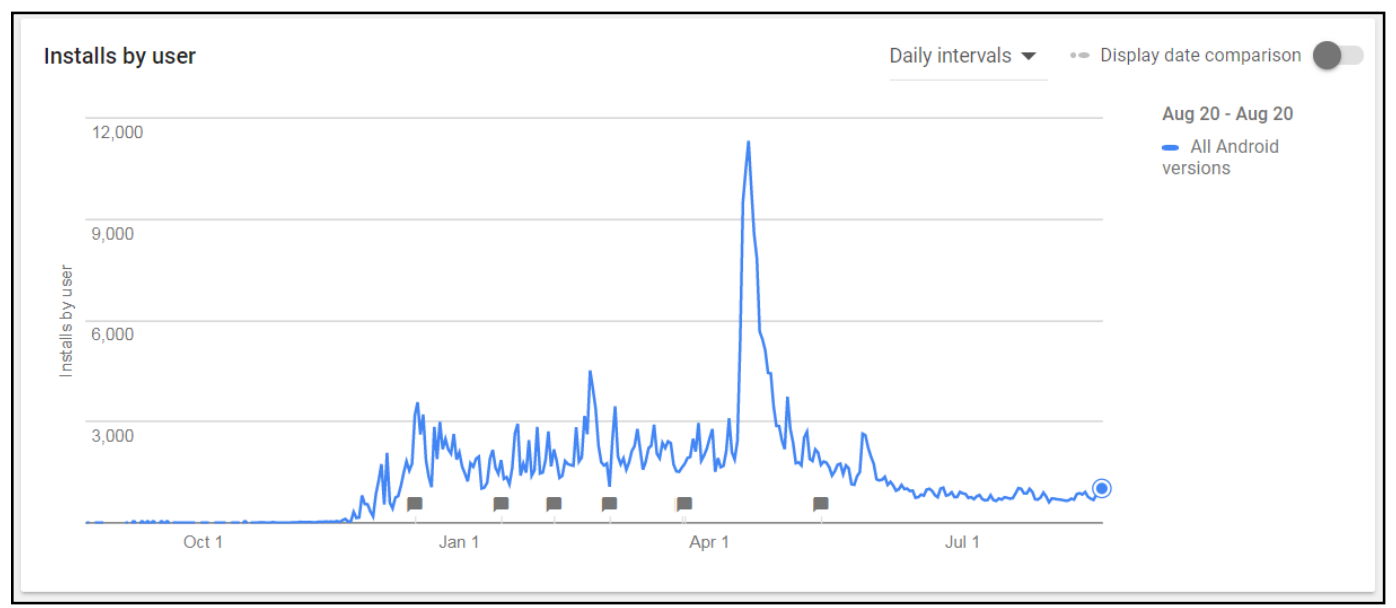

Figure 11. Download statistics of Missing in graph form.

Even though the data generated by Google Play Console is presented in several ways, there are still information that only can be understood by using other methods - and to be able to answer the research question regarding if Missing has reached its purpose of spreading awareness of trafficking other methods of analysis seems to be required.

\subsection{Manual analysis of the review data}

In order to get a deeper understanding regarding the reception of the trafficking theme and purpose of Missing, an analysis of the English reviews has been made. Table 4 presents a quantitative overview of the reviews.

The data set with all review information shows that the game has a total of 7013 star ratings, where 2736 of the ratings do have some kind of review attached. These reviews are in 39 different languages but a majority, 2078 of the reviews (76\%) are written in English. As a comparison, the second most used language is Portuguese with 91 reviews (3\%) followed by Indonesian with 69 reviews (2\%). The spike in downloads shown in Figure 11 stems from the release of the game in the Bengali language. This is not mirrored in the reviews and only 37 of the reviews are written in Bengali. As a comparison, 39 reviews consists of garbage text, i.e. random letters or characters. 
Table 4. Overview of the data from the Missing reviews

\begin{tabular}{|l|c|c|c|c|c|c|}
\hline & $\mathbf{5}$ stars & 4 stars & 3 stars & 2 stars & 1 star & Total \\
\hline $\begin{array}{l}\text { Total number of } \\
\text { star ratings }\end{array}$ & 4821 & 908 & 525 & 207 & 552 & 7013 \\
\hline $\begin{array}{l}\text { Number of ratings } \\
\text { with review }\end{array}$ & 1793 & 340 & 244 & 109 & 250 & 2736 \\
\hline $\begin{array}{l}\text { Number of reviews } \\
\text { in English }\end{array}$ & 1387 & 243 & 179 & 83 & 186 & 2078 \\
\hline $\begin{array}{l}\text { Number of reviews } \\
\text { in English } \\
\text { regarding the } \\
\text { theme }\end{array}$ & 395 & 53 & 21 & 12 & 31 & 512 \\
\hline $\begin{array}{l}\text { Number of reviews } \\
\text { in English } \\
\text { regarding } \\
\text { difficulty in } \\
\text { progression }\end{array}$ & 31 & 25 & 46 & 22 & 10 & 134 \\
\hline $\begin{array}{l}\text { Number of reviews } \\
\text { in English } \\
\text { regarding bugs }\end{array}$ & 5 & 12 & 37 & 19 & 22 & 95 \\
\hline
\end{tabular}

The reviews written in English have been coded based on three categories: reviews regarding the theme, reviews regarding difficulty in progression and reviews regarding bugs, as seen in Table 4. The categories emerged from doing a read-through of all English reviews, and are consistent with categories found in related work regarding app store data analysis (cf. $[25-27,29])$, but in this case also with a specific category regarding the theme. The theme of the game is directly linked to the purpose of spreading awareness regarding trafficking and has a separate code. As identified in previous research (cf. $[6,8,9])$ continuous testing of a game during its development is vital to ensure that the game is fully functional from a technical perspective (i.e. bug free) or a game play perspective (i.e. problems regarding progressing in the game, excluding technical difficulties). These categories have also been used to code the reviews.

Since the category regarding the theme is somewhat subjective, reviews coded to this category contain words or phrasings relating explicitly to the theme, i.e. the theme code does not contain reviews with general praise (or dispraise) of the game. Examples of this are "raising awareness", "trafficking" or "social issue", but as seen in the auto generated review analyses a keyword or even phrase search is not enough to correctly identify and code into topics. An example of a review about the theme not containing common keywords or phrases mentioned above is:

"This game needs to be played by everyone so they can experience the horror and be motivated to do more in real life to help. Disturbing and soul shaking as it should be."

$$
\text { - A Google Play user reviewing Missing (5 stars) }
$$

One observation is that the tone in the reviews are tied to the star ratings given; i.e. a 5 star rating is generally accompanied by a positive review, and a 1 star rating is generally accompanied by a negative review regarding tone and content. There are reviews deviating somewhat from this pattern; mostly reviews that relates to the theme in some way, but are (deliberately?) misinterpreted regarding the context. Examples of this include:

\section{"I'm a pimp! All them bitches and hoes Betta recognize or imma pimp slap them!" - A Google Play user reviewing Missing (5 stars)}


In the 1 star category, several of the reviews raise the concern that the game is not suitable for children (even though it is clearly stated in Google Play that the game is rated 18+), that the theme is not suitable for a game or the two in conjunction. Examples of this are:

"Very bad game not for children and I would like to give 0 stars this game should not be played"

\section{- A Google Play user reviewing Missing (1 star)}

"I feel sorry for those girls who are the victims of this kind of business. To all the parents out there please take care of your baby girl. Mom should watch their girls not tp (sic!) be a victim. We can't stop other people mind just to earn money but we can save our girls. Especially in India. This is not a good game, $u$ are teaching kids online how to become a prostitute and how to seduce men? It's good to show here how cruel the world outside but don't go too far"

- A Google Play user reviewing Missing (1 star)

In total $512(25 \%)$ of the English reviews mention the theme. A majority of these can be found in the 5 star category, where $28.5 \%$ of the reviews mention the theme. The drop-off rate mentioning the theme based on star rating is steep (Figure 12). From $28.5 \%$ of the reviews about the theme in the 5 star category to $21.8 \%$ in the 4 star category. The lowest percentage is in the 3 star category with $11.7 \%$ of the reviews focusing on the theme with a slight increase in the 2 and 1 star categories. The share of reviews focusing on bugs and problems regarding the progression in the game can be found in the 3 and 2 star category, and a similar pattern is seen regarding bugs. Notable is that only $0.4 \%$ of the reviews in the 5 star category focus on bugs and $2.2 \%$ focus on progression trouble.

When analyzing the content of the 3 star category deeper, there seem to be not only a larger focus on the bugs and problems, but these issues also seem to render the theme less important. The following quotes exemplify this:

"Story may be nice. But Rubi is not attracting customer after giving them alcohol.

And have to wait to end of the day. I also try to first attract them and then gave them alcohol and also try to attract after giving alcohol while customer walking. But nothing happened."

- A Google Play user review for Missing (3 stars)

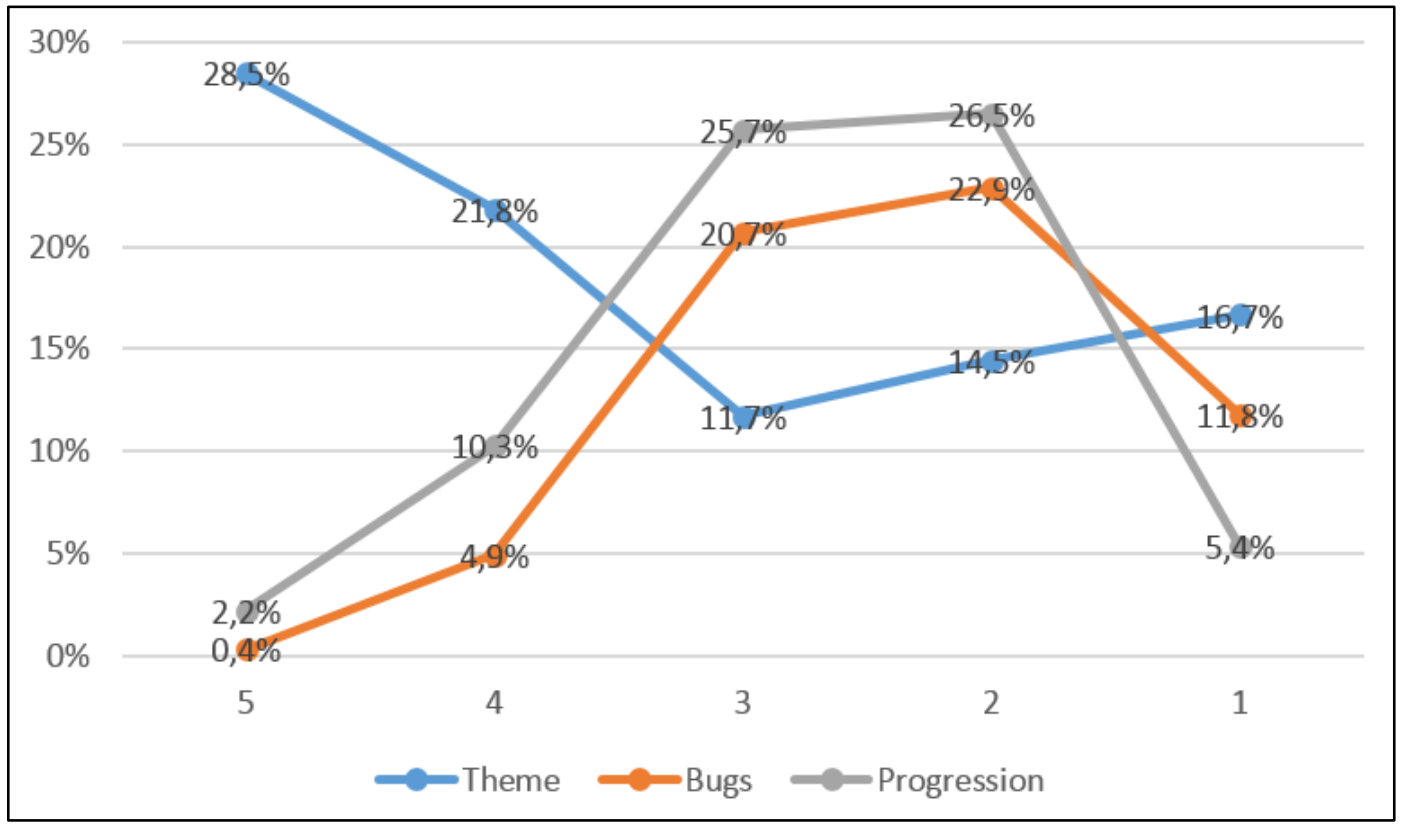

Figure 12. Percentage of reviews in each star rating category (horizontal axis) regarding Theme, Bugs and problems with Progression. 
Even though the user praise the story, the main focus of the review is that the customer NPCs are not attracted to the PC despite treating them with alcohol. The focus is on the game mechanics and its functionality, deprived of any relation to the theme of trafficking. The alcohol feature is not working properly, making it hard for the player to reach the monetary requirement to progress to the next day without punishment.

"Fix the bugs!!! Whenever I buy alcohol or snacks for the customers I can't call them over. Ever. Wastes your money and the harder it gets it's almost impossible to fulfill the challenged. Also, giving drinks and snacks to Meena glitches up the game. Plz fix it."

\section{- A Google Play user review for Missing (3 stars)}

The same tendency can be seen in the comment above also focusing solely on the game mechanics, where the player is unable to attract customers. The comment also implies that the game is unfair because the player has spent in-game currency on a feature that does not work as expected.

The same tendency can be seen in the 2 star category, but with a generally more negative tone in the comments. The difference in tone is clearly seen in the 1 star category where the user reviews are more annoyed containing foul language often with a direct tone towards the developers. Even though $16.7 \%$ of the reviews in the 1 star category still reflect upon the theme there is an overarching negative tone. Examples of this are:

"Am I on a different planet? What the hell is wrong with you people? Awareness of sex trafficking? The awareness is on the news every day but I guess that's not enough. Let's play sex trafficking! Disgusting idiots! I was there and games like this DO NOT HELP! SHAME ON ALL OF YOU!"

- A Google Play user review for Missing (1 star)

Another example of this is a player who relates the game and its topic to the everyday reality:

"This is not entertainment. This is a reality I see everyday...is this your brightest idea?"

\section{- A Google Play user review for Missing (1 star)}

Both those examples are reviews where the player have identified the topic but considers it to be controversial. Reviews like these are often related to the use of a game for raising awareness of the topic but criticize the idea of using games as a medium of spreading a serious topic.

Creating awareness of a horrible problem must not be praised with 5 star reviews - looking at the following two reviews this can be confirmed:

"Maybe its the best game i've ever played! The plot is just so amazing and

unfortunately so true. Those girls in India are going through so much pain and that's bad! This game is just brilliant!! Good job!!"

- A Google Play user review for Missing (5 stars)

Clearly, the player writing this 5 star review have been reached by the message of the game and the 5 star rating have helped the purpose by giving Missing a higher overall score on Google Play. Players are also picking up the theme in the 1 star category, but in a more negative context:

"Depicts the truth of what some women go through in life. Acting out a game of rape, prostitution against will and abduction is vile."

- A Google Play user review for Missing (1 star)

Focusing on the message it can be argued that both players in these examples have got the message and have been affected by it. In conclusion: even a negative rating can be positive seen from the perspective of the game's intended purpose. 


\section{Discussion}

\subsection{The serious purpose in focus}

As stated by Missing's lead game designer, the story based on interviews with trafficking victims was the starting point for the game production and then finding game mechanics to fit this narrative. The player reviews show that while the story is accepted, the game mechanics have been posing a problem for many of the players, which is mirrored in the many comments regarding problems with progression. As seen in Figure 12, players focusing on the theme have more oversight regarding progression and technical problems than players not focusing on the theme. This supports ideas of the importance of a well-functioning game as a basis for a good serious game $[18,19]$, as well as having a design vision where mechanics and story co-operates [6,8]. This is shown in Missing's first and second chapters, primarily in the labyrinth sections (environmental puzzles) and the sections where the players must put a price on sexual services of the PC (micromanagement mechanics). These sections have been difficult for several of the players (i.e. players reviewing in the 2- and 3-star category). Even though an emotional response has been invoked, the emotional response of the players reviewing the game seems to focus mainly on the game mechanics, losing the story and theme perspective. In this case, the intention of creating frustration as an emotional response in the player by making unfair puzzles such as the labyrinth section, seems to cause the players focus even more on the mechanics (in a negative way) rather than the story and theme.

Using the MDA framework not only as an analysis model as in this case, but as a development framework used in serious games to focus on the designer/developer as well as the player perspective, could be relevant to deepen further in future research. In the MDA framework, the use of the term "fun" is highlighted as a problematic term even in development of games without a serious purpose. With the MDA framework [22] a deliberate move away from using a terminology based on "fun" as an aesthetic has been proposed. Even though the MDA framework is not designed specifically with serious games in mind, it is apparent that it is applicable in a serious game setting as well. Since serious games definitions are using "fun" as a goal aesthetic (cf. the serious games continuum [2]) it can be debated if it is an appropriate term in this field.

\subsection{Using the app store data}

The Google Play developer console service provides data related to the game on a general level. In this case where a specific purpose of the game is of interest, the system does not provide sufficient support to accommodate for this. As proposed by Hieftje et al. [8], developing an analysis model combining methods to understand the reception of a serious game is needed.

In the auto-generated textual analyses of the player reviews (see Figure 7), it is notable that the negative reviews related to "stability", "usability" and "uninstalls" have clearly made a negative impact on the game's rating. This indicates the importance of having a wellfunctioning game - if the player is experiencing technical problems or usability issues, the players seem to give up and move on.

The importance of a well-functioning game is also mirrored in the manual analysis of the player reviews. The amount of comments regarding bugs and other progress related issues have a higher ratio in the 2 and 3 star categories. It seems that the players who are engaged in the theme and like the game have more oversight with technical problems, which is shown in both the 5-and 1 star categories where the players are discussing the theme of the game from various perspectives.

This point is especially apparent when looking at the 3 star rating reviews where a majority is picking up on problems encountered rather than the theme or other aspects of the game.

It seems that the players expect the game to function, thus giving reviews where bugs are analyzed as pure game mechanics (cf. the bug where customers was not affected by alcohol 
properly) and not reflecting on the theme. In a non-game setting it would have been quite bizarre to discuss the fact that even though the customers were treated with alcohol it did not yield any results for the business in a brothel, even though the actual mechanics might be the same. In a game setting it is, at least for experienced players, natural to identify and make the developer aware of bugs in the game system. This behavior seems to be present even in a game with a very specific theme.

It is also interesting to note that in this specific case even a negative review can be a positive result in terms of the fulfillment of the purpose.

\section{Conclusions}

This paper presents a case study of Missing, a game about trafficking. We study the project through the research question "How has Missing been received by its players, focusing on the developers' design vision regarding promoting an anti-trafficking theme with a serious game?"

To answer this question, two objectives were achieved: (1) to describe how the game design vision based on real trafficking victim's stories have been implemented into a game, and (2) to investigate how the game and its specific purpose has been received by its players.

For the first objective, an intention from the developers of Missing has been to use game mechanics to make the player "feel" the story, thus finding appropriate game mechanics to support this has been attempted. Since the development of the game has its foundation in a story based on interviews with trafficking victims, it has been vital for the theme to find such game mechanics. Related to the second objective, the analysis of the reviews from Google Play shows that while there is a general praise of the story, it has also been proven difficult to find game mechanics that fully support all aspects of the story. This has especially been apparent in the players having trouble with the progression or with bugs affecting the mechanics.

If the success of a serious game is based on fulfillment of its purpose as proposed by Marsh [2], more research is needed in how to use data available from digital app stores. Even though there are plenty of data available through Google Play, it is difficult to pinpoint the origins and cross reference the data giving precise answers. In this case, where the main purpose is to spread a message and to inform about trafficking it is time consuming and difficult to use available data to get a nuanced view of the reception of the game. As previously identified by Hieftje et al. [8], the combination of using standardized tests and game related data still need more research from a methodological perspective.

Missing is a serious game on many levels, embracing a theme with complex properties, important to highlight on a global scale. With Missing, it is shown that games can (and should, based on its general reception) address complex issues. Even though a game is not the sole solution, it can be a part of the solution. The case of Missing is interesting since it has got a fairly wide spread. With over 500,000 installs it is safe to say that the game and its message has reached many people all over the world.

To conclude, this paper has three main knowledge contributions:

- The identification and characterization of the tension between the designer's intention with a game's mechanics and how they help to convey the message of the game, e.g. the despair of the trafficked girl mirrored in the game mechanics.

- The identification of the complexity of finding relevant comments relating to the serious theme of the game in user reviews. Plain key word search and the automated tools provided by commercial platforms (i.e. Google Play) seem to be insufficient. Hence, there is a need for new and refined methods to identify and classify such comments properly.

The identification and characterization of the tension between the star rating and what is commented on pertaining to the game's theme in the user review. The players tend to be positive towards the theme in the 4 and 5 star categories and also comment on it in the reviews. 
In the middle tier star ratings, the focus on theme seems to be lost and the focus lies on the game as a system of mechanics stripped of its theme and story. In the lower star categories, especially the 1 star Category, the reviews are more likely to focus on the theme but focusing on the negative aspects.

Finally, this paper will hopefully inspire other researchers to reach out to developers in the serious games domain for collaborations to further advance the use of metrics and data from released games on commercial platforms to understand the success of future serious games.

\section{Acknowledgements}

This research has been funded by the Game Hub Scandinavia project under the Interreg Öresund-Kattegat-Skagerrak European Regional Development Fund. Project id: NYPS 20200428.

\section{References}

[1] Deterding, S., Dixon, D., Khaled, R., and Nacke, L., From game design elements to gamefulness: defining gamification. in Proceedings of the 15th international academic MindTrek conference: Envisioning future media environments. 2011. ACM.

[2] Marsh, T., Serious games continuum: Between games for purpose and experiential environments for purpose. Entertainment Computing, 2011. 2(2): p. 61-68. https://doi.org/10.1016/j.entcom.2010.12.004

[3] Susi, T., Johannesson, M., and Backlund, P., Serious games: An overview. 2007, Institutionen för kommunikation och information.

[4] Flying Robot Studios, Missing. 2016, Missing Link Trust: https://play.google.com/store/apps/details?id=com.MissingLinkTrust.Missing [accessed 2018-05-20]

[5] UNODC, Global Report on Trafficking in Persons 2016. United Nations Publication, Sales No. E.16.IV.6, 2016.

[6] de Smale, S., Kors, M.J., and Sandovar, A.M., The case of This War of Mine: A production studies perspective on moral game design. Games and Culture, 2017: p. 1555412017725996. https://doi.org/10.1177/1555412017725996

[7] de la Hera Conde-Pumpido, T., Persuasive gaming: identifying the different types of persuasion through games. International Journal of Serious Games, 2017. 4(1). https://doi.org/10.17083/ijsg.v4i1.140

[8] Hieftje, K., Pendergrass, L.R.D.T., Sawyer, B., and Fiellin, L.E., Development of an HIV Prevention Videogame Intervention: Lessons Learned. International Journal of Serious Games, 2016. 3(2): p. 83-90. https://doi.org/10.17083/ijsg.v3i2.110

[9] Swain, C., Designing Games to Effect Social Change. in DiGRA Conference. 2007.

[10] Rittel, H.W., and Webber, M.M., Dilemmas in a general theory of planning. Policy sciences, 1973. 4(2): p. 155-169. https://doi.org/10.1007/BF01405730

[11] Boyle, E.A., Hainey, T., Connolly, T.M., Gray, G., Earp, J., Ott, M., Lim, T., Ninaus, M., Ribeiro, C., and Pereira, J., An update to the systematic literature review of empirical evidence of the impacts and outcomes of computer games and serious games. Computers \& Education, 2016. 94: p. 178-192. https://doi.org/10.1016/j.compedu.2015.11.003

[12] Van der Kooij, K., Hoogendoorn, E., Spijkerman, R., and Visch, V., Validation of Game for Behavioral Change: Connecting the Playful and Serious. International Journal of Serious Games, 2015. 2(3): p. 63-75. https://doi.org/10.17083/ijsg.v2i3.75

[13] Conklin, J., Wicked problems and social complexity. CogNexus Institute, 2001.

[14] 3909, Papers, Please. 2013, 3909: https://store.steampowered.com/app/ 239030/Papers_Please/ [accessed 2018-05-19]

[15] Numinous Games, That Dragon, Cancer. 2016, Numinous Games: https://store.steampowered.com/app/419460/That_Dragon_Cancer/ [accessed 2018-05-19]

[16] 11 bit studios, This War of Mine. 2014, 11 bit studios: https://store. steampowered.com/app/282070/This_War_of_Mine/ [accessed 2018-05-19] 
[17] Westera, W., Games are motivating, aren't they? Disputing the arguments for digital gamebased learning. International Journal of Serious Games, 2015. 2(2). https://doi.org/10.17083/ijsg.v2i2.58

[18] Schreiner, K., Digital games target social change. IEEE computer graphics and applications, 2008. 28(1). https://doi.org/10.1109/MCG.2008.4

[19] Charsky, D., From Edutainment to Serious Games: A Change in the Use of Game Characteristics. Games and Culture, 2010. 5(2): p. 177-198. https://doi.org/10.1177/1555412009354727

[20] Djaouti, D., Alvarez, J., and Jessel, J.P., Classifying serious games: the G/P/S model. Handbook of research on improving learning and motivation through educational games: Multidisciplinary approaches, 2011. 2: p. 118-136.

[21] Michael, D.R., and Chen, S.L., Serious Games: Games That Educate, Train, and Inform. 2005 Muska \\& Lipman/Premier-Trade.

[22] Hunicke, R., LeBlanc, M., and Zubek, R. MDA: A formal approach to game design and game research. in Proceedings of the AAAI Workshop on Challenges in Game AI. 2004.

[23] AppAnnie. 2018 [cited 2018 0829]; Available from: www.appannie.com.

[24] Appfigures. 2018 [cited 2018 0828]; Available from: $\underline{w w w . a p p f i g u r e s . c o m}$.

[25] Fu, B., Lin, J., Li L., Faloutsos, C., Hong, J., and Sadeh, N. Why people hate your app: Making sense of user feedback in a mobile app store. in Proceedings of the 19th ACM SIGKDD international conference on Knowledge discovery and data mining. 2013. ACM. https://doi.org/10.1145/2487575.2488202

[26] Maalej, W., and Nabil, H., Bug report, feature request, or simply praise? on automatically classifying app reviews. in 2015 IEEE $23 r$ international requirements engineering conference (RE). 2015. IEEE.

[27] Guzman, E., and Maalej, W., How do users like this feature? a fine grained sentiment analysis of app reviews. in Requirements Engineering Conference (RE), 2014 IEEE 22nd International. 2014. IEEE.

[28] Swedish Research Council, Codex - rules and guidelines for research. 2017, Swedish Research Council.

[29] Pagano, D., and Maalej, W., User feedback in the appstore: An empirical study. in Requirements Engineering Conference (RE), 2013 21st IEEE International. 2013. 